\title{
EXPERIMENTAL STRESS ANALYSIS OF ROCKET MOTOR CASING USING ELASTO-PLASTIC STRAIN THEORY
}

\author{
DR. G. LAXMAIAH ${ }^{1}$, DR S SOLOMON RAJ ${ }^{2} \&$ DR. P V R. RAVINDRA REDDY ${ }^{3}$ \\ ${ }^{1}$ Professor, Chaitanya Bharathi Institute of Technology, Hyderabad, Telangana, India \\ ${ }^{2}$ Associate Professor, Chaitanya Bharathi Institute of Technology, Hyderabad,India \\ ${ }^{3}$ Professor, Chaitanya Bharathi Institute of Technology, Hyderabad, Telangana, India
}

\begin{abstract}
The purpose of rocket motors isto generate thrust or impulsive force to be passed on aninclined velocity to flight vehicle to transport its payload to its requiredtarget. It will be subjected to high pressure loads and temperature during the operating conditions of the motor mechanism. So, while selecting the material for the manufacturing of motor case, utmost care has to be taken, because the material chosen has to withstand all kinds of structural and thermal loads acting on it.15CDV6 steel is one of the latest trends, used in the design of rocket motors due to its high strength and hardness. The unique quality of 15CDV6 steel is that, it is a hypo-elastic material. This paper intends to analyze and evaluate the performance of 15CDV6 steel in its elasto-plastic range. Three specimens of the material were evaluated with the help of tensile tests and strain gauge data. For calculations, plane stress condition has been considered. From the resulting design parameters, a code was developed on the digital computer using Microsoft Excel, to create data sheets which produce stress data as output, when strain data is given as input. This code is also helpful in quickly analyzing the material behaviorby finding the factor of safety for the casing.

KEYWORDS: Motor Casing, Strain Gauges, Elasto- Plastic Range \& Microsoft Excel
\end{abstract}

Received: May 05, 2020; Accepted: May 25, 2020; Published: Jul 18, 2020; Paper Id.: IJMPERDJUN2020381

\section{INTRODUCTION}

A rocket engine is a standard energy shift system. High pressure as well as hightemperature combustion product gases has been enlarged viaconverging-diverging nozzle. With the procedure, internal energy of the gas will be transformed to kinetic energy of the fatigue flow; alsothe thrust was created through gas force over the surfaces subjected to this gas [8]. Solid propellantrocket engine was majorly utilized than the other rocket engines because of its comparatively easy model, higher reliability, simplicity ofproduction also prepared to work with on demand. Since solid-fuel rockets may stay in stock for extended durations, and then reliably initiate on short note,they've been often utilized in military programs like missiles. Nevertheless, it is often utilized together with strap-on boosters to maintain payload potential. An easy solid rocket engine is made up of motor casing, nozzle, inner insulation,propellant grain as well as igniter. The choice of substance for rocket engine parts relies upon high particular power, high particular modulus, fabricationuncomplicated, simple accessibility, crucial needs as well service requirements [6]. Majorly utilized substances for solid rocket engine parts were 15CDV6 steel, M250 Steel, Titanium alloy, Aluminium Alloys. The15CDV6 steel was high powered steel including fewer concentrations of chromium,molybdenum, and vanadium because alloying components. Due to its great power-ductility integration and also simplicity of fabrication, the substance was broadly utilized in rocket-motor hardware at the Indian space program. Thismetal locates numerous programs in the aerospace as well as motorsports businesses inthese elements 
like roll cages, pressure vessels, suspension systems such as desire bones along with sub-frames, rocket motor casings $[<\mathrm{b}\rangle 3</ \mathrm{b}\rangle]$. It's a low-alloy steel, where the ratio by weight ofwhole alloying components united was lesser than $5 \%$ $[<b>4</ b>]$. Its chemical composition is shown in table1, and mechanicalattributes are displayed in table 2.

Table 1: Chemical Composition of 15CDV6 Steel

\begin{tabular}{|c|c|c|c|c|c|c|c|c|c|}
\hline Composition & C & Cr & Mo & V & Fe & Mn & S & P & Si \\
\hline \multirow{2}{*}{ Weight $\%$} & $0.12-$ & $0.25-$ & $0.8-$ & $0.2-$ & Balan & $0.08-$ & 0.015 & 0.02 & 0 \\
& 0.18 & 1.5 & 1.0 & 0.3 & ce & 1.1 & $\max$ & $\max$ & \\
\hline
\end{tabular}

Table 2: Mechanical Properties of 15CDV6 Steel at Room Temperature

\begin{tabular}{|l|c|c|}
\hline \multicolumn{1}{|c|}{ Property } & $\begin{array}{c}\text { Tempering at 650oC and } \\
\text { air cooling }\end{array}$ & $\begin{array}{c}\text { Tempering at 625oC } \\
\text { and oil cooling }\end{array}$ \\
\hline Tensile strength $(\mathrm{N} / \mathrm{mm} 2)$ & 105 & 115 \\
\hline Yield point $(\mathrm{N} / \mathrm{mm} 2)$ & 85 & 100 \\
\hline Elongation \% & 16 & 16 \\
\hline Impact strength $(\mathrm{N} / \mathrm{mm} 2)$ & 9 & 13 \\
\hline
\end{tabular}

The rocket motor casing is built up by welding of number of sheets. Firstly, a long rectangular sheet is rolled into a cylinder and then a long seam of weld is done. This welded cylinder is then welded to a similar cylinder by a circular seam. This is continued until the desired size of the rocket motor casing is obtained. Then at the ends of the casing, the thrust skirt and other parts will be welded. After welding the heat treatment for the entire case has to be carried out. Strain gauges are scaled mainly in the cylindrical part, closer the long seam weld joint as the motor case under high internal pressure.

A state of plane pressure exits at each stage on the surface of a member subjected to the given loading. Generally, the condition of plane strain is biaxial along with the parallel deformations are tri-axial. At anyprovided stage, the direction of principalnormal stresses $\sigma_{\max }$ and $\sigma_{\min }$ lie in a plane, where is tangential to that point. Ininvestigational strainexperimentation utilizingtoil gauges, normally, toils in the surface, i.e., in the tangential plane were discovered in minimum three ways, and from the principal ways 1 and 2, the principal toils $\epsilon_{1}$ and $\epsilon_{2}$ may be decided.

In this work, as the strain gauges have been used, the evaluation of stresses depends on the positioning of the gauges on the specimen, as direction is one of the most essential parameters for such setups. A foil type strain gauge was used for this study.From elementary mechanics of materials, the strain at an angle is provided as,

$$
\epsilon_{\theta}=\frac{\epsilon_{x}+\epsilon_{y}}{2}+\left(\frac{\epsilon_{x}-\epsilon_{y}}{2}\right) \cos 2 \theta+\frac{1}{2} \gamma_{x y} \sin 2 \theta
$$

In every scenario, the computations were clarified if the $\mathrm{X}$ axis was selected to correspond with $\theta=0$. Afterwards, for both kinds of rosette configurations, then the required equation reduces to $\epsilon_{0}=\frac{1}{2}\left(\epsilon_{x}+\epsilon_{y}\right)+\frac{1}{2}\left(\epsilon_{x}-\epsilon_{y}\right)=\epsilon_{x}$

and $\epsilon_{\mathrm{x}}$ is directly obtained from the $\epsilon_{0}$ strain gauge reading. Similarly, for the rectangular rosette $\epsilon_{\mathrm{y}}$ is directly obtained from the $\epsilon_{90}{ }^{\circ}$ reading[1].The toil in the $\mathrm{x}$ directionin a substanceexposed to three mutually perpendicular pressures in the $x, y$ and $z$ directions is provided as $\epsilon_{x}=\frac{1}{E}\left(\sigma_{x}-v \sigma_{y}-v \sigma_{z}\right)$ 
Identical equations put in for $\epsilon_{\mathrm{y}}$ and $\epsilon_{\mathrm{z}}$. Consequently, the principal toil at a provided direction could be located in terms of the principal pressures. For two proportional scenario,

$$
\sigma_{1}=\frac{\left(\epsilon_{1}+v \epsilon_{2}\right) E}{\left(1-v^{2}\right)} \text { and } \sigma_{2}=\frac{\left(\epsilon_{2}+v \epsilon_{1}\right) E}{\left(1-v^{2}\right)}(1)
$$

Von mises' theory, commonly, mentioned for the tri-axial strain stateusing the uni-axial equivalent strain $\sigma_{\mathrm{v}}$ was officiallywith the strain-energy theory. Comparing with similar theories for formulation of equivalent strain (e.g., common strainor shear strain theories), it indicates the better outcomes for isotropic ductile metallic substances. In the above equation, through replacing with the yield strain $\sigma_{\mathrm{y}}$, the yield state was acquired.For plane-strainstate with $\sigma_{3}=0$, above equation modifies to $\sigma_{v}^{2}=\sigma_{1}^{2}+\sigma_{2}^{2}-\sigma_{1} \sigma_{2}(2)$

Becausein the investigational strainexaminations utilizing toil gauges, strain is being estimated, it was extremely stable to state a deformation basis than the equivalent strain. Hence, upon above equation, the equivalent strain $\boldsymbol{\epsilon}_{\boldsymbol{v}}$ could be mentioned as

$$
\epsilon_{v}=\frac{\sigma_{v}}{E}(3)
$$

As Hooke's equations states a linear association among pressures as well as deformations, the equivalent toil, $\epsilon_{\mathrm{v}}$ could be decided instantly from the principal toilsz $\epsilon_{\mathrm{V}}^{2}=\epsilon_{1}^{2}+\epsilon_{2}^{2}+\epsilon_{3}^{2}-\epsilon_{1} \epsilon_{2}-\epsilon_{2} \epsilon_{3}-\epsilon_{1} \epsilon_{2}$

Since, $z=(1+\vartheta)^{2}$, The above equation can now be written as

$$
\epsilon_{\mathrm{v}}=\frac{1}{(1+9)} \sqrt{\epsilon_{1}^{2}+\epsilon_{2}^{2}+\epsilon_{3}^{2}-\epsilon_{1} \epsilon_{2}-\epsilon_{2} \epsilon_{3}-\epsilon_{3} \epsilon_{1}}(4)
$$

The strain $\epsilon_{3}$ which cannot be estimated using toil gauges is removed through utilizing the formula $=$ $\sqrt{N_{q}\left(\epsilon_{1}^{2}+\epsilon_{2}^{2}\right)+N_{g}\left(\epsilon_{1} \epsilon_{2}\right)}(5)$

Where, $N_{q}=\frac{1-\vartheta(1-\vartheta)}{\left(1-\vartheta^{2}\right)^{2}}(6)$

$$
N_{g}=\frac{-1+\vartheta(4-\vartheta)}{\left(1-\vartheta^{2}\right)^{2}}(7)
$$

In this, $N_{q}$ and $N_{g}$ were expressions of Poisson's ratio.For stable equivalent toil, $\in_{\mathrm{v}}$ was stable as well as the equation indicates an ellipse whereform was decided using Poisson's ratio. This was very simply identified, while the equation was divided by $\epsilon_{\mathrm{v}}$ and squared

$$
N_{q}\left(\frac{\epsilon_{1}^{2}}{\epsilon_{v}^{2}}+\frac{\epsilon_{2}^{2}}{\epsilon_{v}^{2}}\right)+N_{g}\left(\frac{\epsilon_{1} \epsilon_{2}}{\epsilon_{v}^{2}}\right)=1(8)
$$

The principal axes of the ellipse were prepared at $45^{\circ}$ to the $\epsilon_{1}-\epsilon_{2}$ co-ordinate system along with their lengths were $2 \mathrm{a}=\frac{2}{\sqrt{N_{q}+0.5 N_{g}}}$; and $2 \mathrm{~b}=\frac{2}{\sqrt{N_{q}-0.5 N_{g}}}$ respectively. Thus by including variable features, irrespective of the stable modulus of elasticity $\mathrm{E}$ and Poisson's ratio $\vartheta$, the elasto-plastic substance reaction could be officiallyexplained in the similar formatlike linear-elastic behavior as

$$
\epsilon_{v}=\frac{\sigma_{v}}{S}(9)
$$

Where, $\mathrm{S}$ is the secant modulus. The total equivalent toil $\epsilon_{\mathrm{v}}$ in accordance with equation is made of elastic as well 
as a plastic element. Consistently, an integrated Poisson's ratio $\vartheta_{\mathrm{g}}$ for the entire deformation lies among Poisson's ratio $\vartheta$ also $0.5 . \vartheta_{\mathrm{g}}$ relies upon the magnitude of deformation thenreaches 0.5 for larger plastic-strain elements, $\vartheta \leq \vartheta_{g}\left(\epsilon_{v}\right) \leq$ 0.5.The secant modulus describes only a point on the stress-strain curve, hence itself an expression of the equivalent toil $\epsilon_{\mathrm{v}}$. for a known value of equivalent strain, the values of Secant modulus could be read off from the stress-strain curve. With the Secant modulus as well as integrated Poisson's ratio, Hooke's stress-strain associations are reasonable for plane-stress states. Thus for the elasto-plastic range, the principal pressures will be

$$
\begin{aligned}
& \sigma_{1}=\frac{s}{1-\vartheta_{g}^{2}}\left(\epsilon_{1}+\vartheta_{g} \epsilon_{2}\right)(10) \\
& \sigma_{2}=\frac{s}{1-\vartheta_{g}^{2}}\left(\epsilon_{2}+\vartheta_{g} \epsilon_{1}\right)(11)
\end{aligned}
$$

Where, the combined Poisson's ratio is given by $\vartheta_{g}=0.5-(0.5-\vartheta) \frac{S}{E}(12)$

To be valid, the above two equations pre-suppose isotropy;hence the co-axiality was assured. Thus the principal pressures as well as principal toils have similar ways.

\section{METHODOLOGY AND EXPERIMENTATION}

The heat treated specimen, as shown in figure 2 is tested onBiSS Universal testing machine shown in figure 4, with the load on the specimen is increased continuously, until the fracture load is obtained. The strain of the material versus the stress induced curve is simultaneously obtained on the monitor, and the stress-strain data is plotted accordingly and is shown in figure 3. From the tensile test data, curve fitting was done and the factor of safety (n) value was evaluated.All specimen tensile test data was taken for the evaluation of factor of safety, and $n$ value will be finalized based on method of least squares for error approximation.Strain gauges have been installed at different locations on the Rocket motor as shown in figure1, and pressure was applied. The pressure was first increased and then decreased in steps. The variation of strains with respect to the pressure has been recorded and shown in table5 and 6.In this work, a code is developed based on the theoretical equations [2] with Microsoft Excel, with the flow chart mentioned to run on the digital computer. Once the strain gauge readings are substituted into the code, the final results of stresses will be displayed as shown in table 7 and 8.

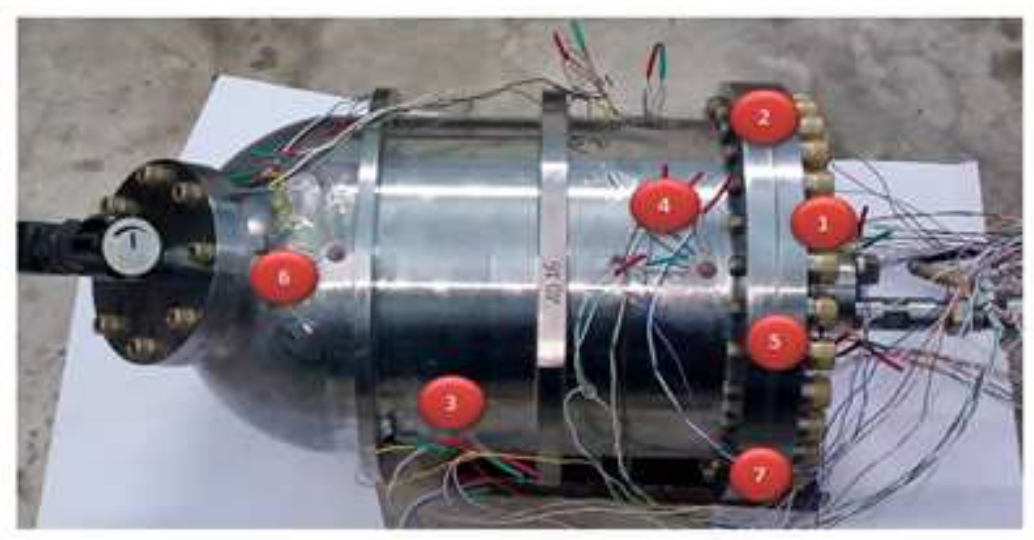

Figure 1: strain gauges attached at different locations of rocket motor casing

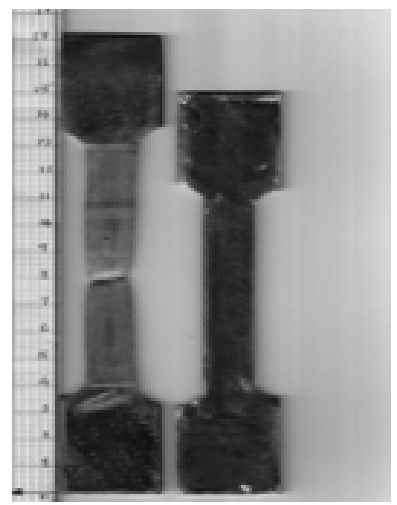

Figure 2: specimens tested under UTM

\section{RESULTS AND DISCUSSIONS}

The final stage of analysis consists of the evaluation of the factor of safety, and checking for itbeing in the permissible 
limits. The permissible limits of the factor of safety have been found from theoretical equations and checked the value from experimentation. The leastsquares procedure is a form of mathematical regression examinations that locates out the line of best suits for a set of information, giving a visual presentation of the association among the data points. Every stage of informationis indicative of this association among a famous individual factor as well as an unknown dependent factor. It offers the general reason for the position of the line of best match, one of the data points being analyzed. The major typical use of this least squares procedure, that can be known as linear or ordinary, intends to make a direct line which reduces the amount ofthe squares of the mistakes created through the outcomes of the related equations,like the squared residuals caused by distinctions from the noticed value,and the value expected depending on the design. The technique of regression examinationsstarts with a pair of data points to be drawn in an $\mathrm{x}$ - and $\mathrm{y}$-axis graph. Anevaluation with the least squares procedure will find a line of best fit, which clarifies the possible connection among an independent factor as well as adependent factor.

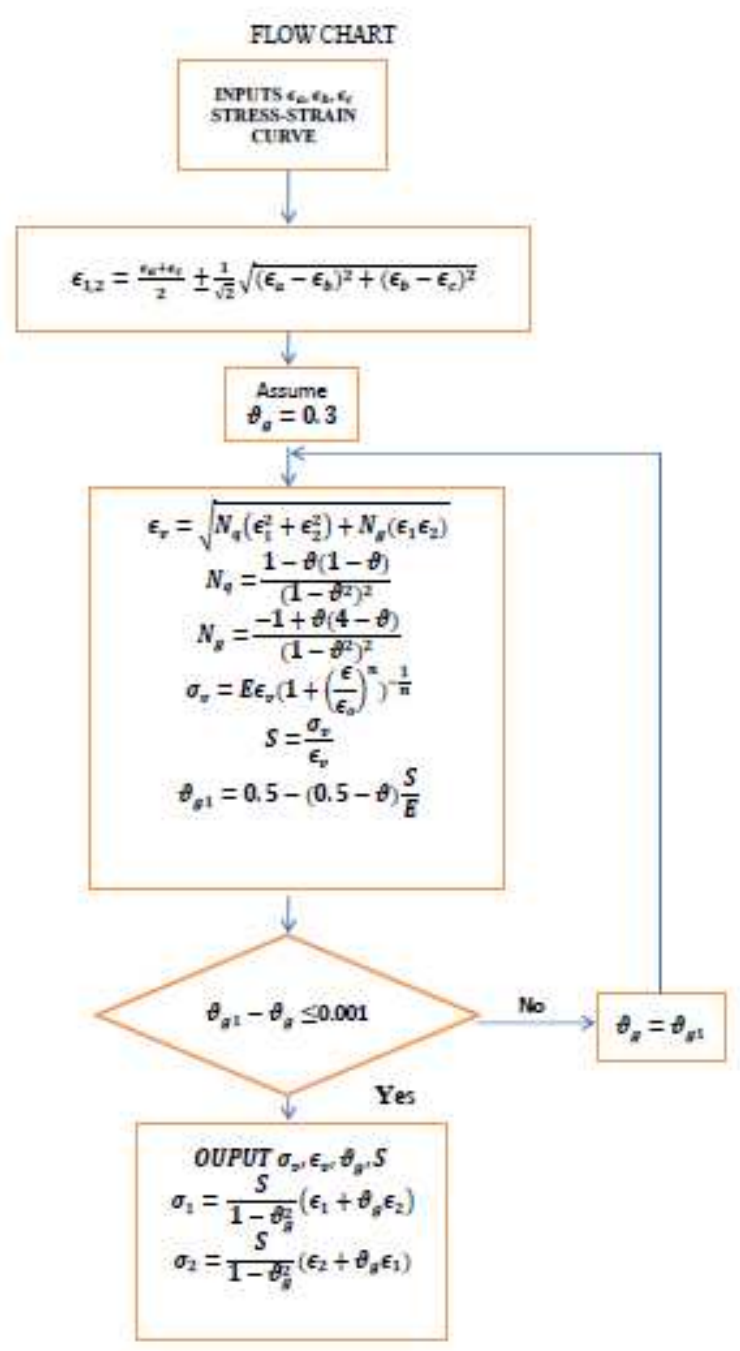

In regression examinations, dependent factors wereelected on the vertical $\mathrm{Y}$-axis and independent variables were selected on the horizontal $\mathrm{X}$-axis. These selections will form the equation for the line of best match. The equation for the line $y=m x+b, \mathrm{~m}=$ slope or gradient, $\mathrm{b}=\mathrm{y}$-intercept (where the line crosses the $\mathrm{y}$-axis).

The slope can be calculated as, $\mathbf{m}=\frac{N \sum(x y)+\sum x \sum y}{N \sum x^{2}+\left(\sum x\right)^{2}}$ 
$\mathrm{N}$ is the number of points. The Intercept $\mathrm{b}$ can be calculatedas $\mathrm{b}=\frac{\sum y-\boldsymbol{m} \sum x}{\boldsymbol{N}}$. The slope of the graph for the specimen 1 is calculated within the elastic range, using a scatter diagram from figure 3 . The line equation of elastic range is $y=209091 x-17.455$. Hence, Young's modulus $=209.091 \mathrm{Mpa}$. The factor of safety $\boldsymbol{n}=\frac{\ln (2)}{\ln \left(\frac{E \epsilon_{0}}{\sigma_{0}}\right)}$, the values of $\sigma$ and $\epsilon$ are obtained from a point on the curve, intersecting at $0.2 \%$ offset yield stress. From the above data we get $\mathrm{n}=2.114143537$.Similarly we can calculate the young's modulus and factor of safety for specimen2 and 3, and shown in table 3 .

Table 3: The Young's Modulus and $n$ Values

\begin{tabular}{|l|c|c|c|}
\hline & Specimen 1 & Specimen 2 & Specimen 3 \\
\hline Modulus of Elasticity(MPa) & 209.091 & 219.623 & 226.455 \\
\hline Factor of safety(n) & 2.1141 & 2.1581 & 2.1543 \\
\hline
\end{tabular}

It is observed that then value is slightly different for different specimens because, this error is vanished by finding the best fitting straight line, through the set of data points obtained. Hence from least square curve fitting, we finalize the best value of $n$ suiting the specimens considered. The final values of Modulus of elasticity (E) are 220Mpa and the factor of safety (n) is 2.145.The following is a clarified method that was designed on a digital computer, for the pressure examinations in the elasto - plastic range, with the help of toil gauges. Depending on the biaxial strain area, an equivalent toil $\epsilon_{\mathrm{v}}$ wasascertained through replacing anestimated principal toils $\epsilon_{1}$ along with $\epsilon_{2}$ into the equation. The values of $\epsilon_{1}$ and $\epsilon_{2}$ are obtained from the strain gauge data. Considering at location 3 from table 5,for a pressure of 30ksc,the values of $\epsilon_{\mathrm{a}}, \epsilon_{\mathrm{b}}$ and $\epsilon_{\mathrm{c}}$ are 1818,1152 and 478,respectively. Then, from equation (4),

$$
\epsilon_{1,2}=\frac{\epsilon_{a}+\epsilon_{c}}{2} \pm \frac{1}{\sqrt{2}} \sqrt{\left(\epsilon_{a}-\epsilon_{b}\right)^{2}+\left(\epsilon_{b}-\epsilon_{c}\right)^{2}}
$$

$\epsilon_{1}=0.001818$ and $\epsilon_{2}=0.000477$

Assuming $\vartheta=0.3$, Equation (5) can be written as,

$\epsilon_{v}=\sqrt{N_{q}\left(\epsilon_{1}^{2}+\epsilon_{2}^{2}\right)+N_{g}\left(\epsilon_{1} \epsilon_{2}\right)}=0.00186$

Where, $N_{q}=\frac{1-\vartheta(1-\vartheta)}{\left(1-\vartheta^{2}\right)^{2}}=0.95399$

$$
N_{g}=\frac{-1+\vartheta(4-\vartheta)}{\left(1-\vartheta^{2}\right)^{2}}=0.13283
$$

In this, $N_{q}$ and $N_{g}$ are functions of positions ratio, which is originated from the distortion energy theory. The pressure $\sigma_{\mathrm{y}}$ correlating to $\epsilon_{\mathrm{v}}$ has acquired from the uniaxial stress-strain curves of the substance. In the plastic area, Secant modulus of elasticity $\mathrm{S}$ has considered equal to $\sigma_{\mathrm{y}} / \epsilon_{\mathrm{v}}$. Accordingly, the combined Poisson's ratio for the entire deformation rest among Poisson's ratio $\vartheta$ and the 'plastic' Poisson's ratio 0.5[2].

From equation (12), $\vartheta_{g}=0.5-(0.5-\vartheta) \frac{S}{E}=0.3095$

The three unknowns, $\epsilon_{\mathrm{v}}, \sigma_{\mathrm{v}}$ and $\mathrm{S}$ have been decided from the above equations and the uniaxial stress-strain curve. A constitutive relationship, which offers the pressure as an explicit expression of the toil was very helpful in the 
investigation. This association was $\sigma=E \epsilon\left(1+\left(\frac{\epsilon}{\epsilon_{o}}\right)^{n}\right)^{-\frac{1}{n}}=38.815$

Where $\sigma$ was the pressure, $\mathrm{E}$ is the Young's modulus, $\in$ was the toil, $\epsilon_{0}$ is the plastic toil as well as $\mathrm{n}$ was a parameter describing the form of the nonlinear stress-strain association. However, in this equation, the stress reaches the plastic stress asymptotically with raising toil. The consistent $\mathrm{n}$ and $\epsilon_{0}$ can be determined approximately by curve fitting by the method of least squares. $n=\frac{\ln (2)}{\ln \left(\frac{E \epsilon_{o}}{\sigma_{o}}\right)}=2.145$

Here, the values of $\sigma_{0}$ and $\in_{0}$ were acquired from the point on the curve at the place where the curve intersects the line of $0.2 \%$ Offset yield stress. Theprecision of illustration of the stress-strain curve explained in the stress equation above can be enhanced further through alternating the values of $\epsilon_{0}$ as well as $n$ by least-square curve fit. The value of Secant modulus Sfor indicated values of $\mathrm{E}, \epsilon_{0}$ can be directly obtained as $S=E\left(1+\left(\frac{\epsilon}{\epsilon_{o}}\right)^{n}\right)^{-\frac{1}{n}}=20868.7$

Using the above equations, one might obtain the Secant Poisson's ratio $\vartheta_{\mathrm{g}}$ in terms of $\epsilon_{\mathrm{v}}$ as

$$
\vartheta_{g}=0.5-(0.5-\vartheta)\left(1+\left(\frac{\epsilon}{\epsilon_{o}}\right)^{n}\right)^{-\frac{1}{n}}(\text { From equation }(12))
$$

Also, from equation (5), $\epsilon_{v}=\sqrt{N_{q}\left(\epsilon_{1}^{2}+\epsilon_{2}^{2}\right)+N_{g}\left(\epsilon_{1} \epsilon_{2}\right)}$

Since in the above two equations, $\vartheta_{\mathrm{g}}$ and $\epsilon_{0}$ are inter-dependent, an iteration procedure was required to assess the correct values of $\epsilon_{0}$ and $\vartheta_{\mathrm{g}}$ thatcan fulfill both the equations. Once the value of $\epsilon_{0}$ was accepted, the Secant modulus of elasticity $S$ could be calculated. The iteration process for the evaluation of $\vartheta_{\mathrm{g}}$ and $\epsilon_{0}$ was as mentioned. Originally, the integrated Poisson's ratiowas presumed as $\vartheta$ as well as replaced with the equation (2) to get $\epsilon_{0}$ for the indicated values of $\epsilon_{1}$ and $\epsilon_{2}$. The value of $\epsilon_{0}$ was replaced with equation (1) to get $\square_{\mathrm{g}}$. Utilizing the value of $\square_{\mathrm{g}}$, substituting in equation (2), $\in_{0}$ is obtained. This iteration procedure was to be carried on till the un-known $\square_{\mathrm{g}}$ and $\in_{0}$ fulfill both the equations with the determinedlevel of perfection. Three to four iterations might be needed to acquire correct values of $\square_{\mathrm{g}}$ along with $\in_{0}$. Obtaining values are,

$$
\square_{\mathrm{g}}=0.3095, \mathrm{~S}=20868.7 \text { and } \epsilon_{0}=0.005
$$

With the Secant modulus as well as integrated Poisson's proportion, the principal pressures $\square_{1}$ as well as $\square_{2}$ could be computed with the Hooke's equations from the biaxial pressure states were

$$
\square_{1}=\frac{\square}{1-\square^{2}}\left(\square_{1}+\square \square_{2}\right)=45.365 \mathrm{Ksi} \text { and } \square_{2}=\frac{\square}{1-\square^{2}}\left(\square_{2}+\square \square_{1}\right)=23.995 \mathrm{Ksi}
$$

Because the formulation of the fact was common, the evaluation of principal pressures and estimated principal toils in elastic and elasto-plastic ranges could be decided. The iteration process defined here was programmed on a digital computer using Microsoft Excel.From the code, the evaluation of stresses from strains has been done and the results have shown in table7 and 8. An element of protectivereveals how much powerful a structure was, than it requires to be for a considered load. For the given material,the 0.2\% Proof Stress is found to be $1014 \mathrm{MPa}$ and Ultimate Tensile Strength is 1150MPa.By referring table 7, The Factor of safety at location 1 , at a pressure value of $51 \mathrm{ksc}$ is :

Factor of safety $(\mathrm{n})$ at $0.2 \%$ proof stress $=\frac{0.2 \% \text { proof stress }}{\text { actual stress }}=\frac{1014}{80.7 \times 9.81}=1.28$, and theFactor of safety (n) at $0.2 \%$ UTS is 


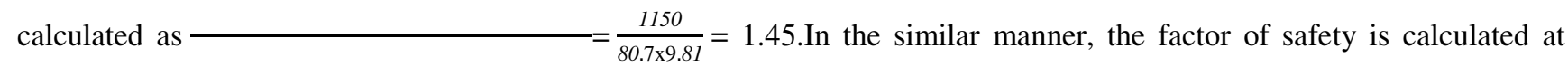
different locations of casing and shown in table 4 .

Table 4: Factor of Safety evaluated at distinct Places

\begin{tabular}{|c|c|c|c|c|c|c|c|c|}
\hline Location & $\mathbf{1}$ & $\mathbf{2}$ & $\mathbf{3}$ & $\mathbf{4}$ & $\mathbf{5}$ & $\mathbf{6}$ & $\mathbf{7}$ & Minimum FOS \\
\hline $0.2 \%$ PS & 1.28 & 3.61 & 1.62 & 1.61 & 1.86 & 1.49 & 2.14 & 1.28 \\
\hline UTS & 1.45 & 3.57 & 9.07 & 4.10 & 1.60 & 2.95 & 1.84 & 1.45 \\
\hline
\end{tabular}

\section{CONCLUSIONS}

- Investigational pressureexaminations wereconducted on the rocket motor casing created of $15 \mathrm{CDV} 6$ steel, from which it is found that, the principal stresses and Factor of safety are in the permissible limits at various locations

- The Factor of Safety obtained is much lower than that can be obtained from the analysis in the linear region. Thus, the design that is a result of such an analysis is safer

- It is also observed that the stresses calculated are found to be more concentrated at critical sections like bolts and welded areas of the rocket motor casing.

- Factor of Safety for $0.2 \%$ proof stress was found to be 1.28 , while the Factor of Safety for Ultimate Tensile Strength was found to be 1.45

- This code can be here on used for the stress-strain analysis conveniently, and also consumes less time, manually calculating the parameters.

\section{REFERENCES}

1. S.Keil and O.Benning (1979)"The Evaluation of Elasto-plastic Strains Measured With Strain Gauges". Experimental mechanics, 19(8) pp 265-270.

2. Dr B.N Rao (1991) A Simplified Procedure for Stress Analysis in the Elasto-plastic Range With the Aid of Strain Gauges, Experimental Techniques, may/june 91 pp 38-39

3. Kc, Vishwanath. "Investigation Of Effect Of Friction Stir Drilling Parameters On Elastoplastic Behaviour Of Al Alloy." International Journal of Mechanical and Production Engineering Research and Development (IJMPERD) 8.1, Feb 2018, 1059-1064

4. Roy Hartfield, Rhonold Jenkins,John burkhalter, Winfred foster (2003), A Review of Analytical Methods for Solid Rocket Motor Grain Analysis, 39 $9^{\text {th }}$ AIAA/ASME/SAE/ASEE Joint propulsion conference, Huntsville, Alabama,2003- 4506

5. A.P. Beena, M.K. Sundaresan \& B.Nageswara Rao,(1995) "Destructive Tests of 15CDV6 Steel Rocket Motor Cases and Their Application To Lightweight Design” international journal of pressure vessels and piping,volume 62, issue 3, page- 313-320

6. Kumar, A. Praveen, and S. Sivasankar. "Importance of anisotropic coefficients for material constitutive models in forming and crushing simulations." Int. J. Mech. Prod. Eng. Res. Develop. 9.6 (2019): 765-778.

7. G.Laxmaiah, Dr P Ravinder Reddy, MNSV Kiran kumar (2011) "Optimization of Parameters Effecting the Noise in Hermitically Sealed Reciprocating Compressor Using Taguchi Technique”. International Journal of Multidisciplinary Research and Advances in Engineering (IJMRAE), ISSN 0975-7074, Volume 4, Number IV,pp 383-394

8. Aljibori, Hakim S. Sultan. "Non-Linear Elastic-Plastic Behaviour Of Aluminium Sheet Metal Using Finite Element Analysis. "International Journal of Mechanical and Production Engineering Research and Development (IJMPERD) 9. 1, Feb 
2019, 281-290

9. Sidhant Singh (2013), Solid Rocket Motor for Experimental Sounding Rockets, Advances in Aerospace Science and Applications. Volume 3, Number 3, pp. 199-208

10. P. Mahesh Babu, G. Bala Krishna and B Siva Prasad(2015) Design \& Analysis of Solid Rocket Motor Casing for Aerospace Applications, International Journal of Current Engineering and Technology E-ISSN 2277 - 4106, P-ISSN 2347 - 5161,, Vol.5, No.3 pp 1947-1954

11. Dinesh Kumar B, Shishira Nayana B and Shravya Shree D(2016) Design and Structural Analysis of Solid Rocket Motor Casing Hardware used in Aerospace Applications-Journal of Aeronautics \& Aerospace Engineering, ISSN: 2168-9792Volume 5, Issue 2, 1000166

\section{APPENDIX}

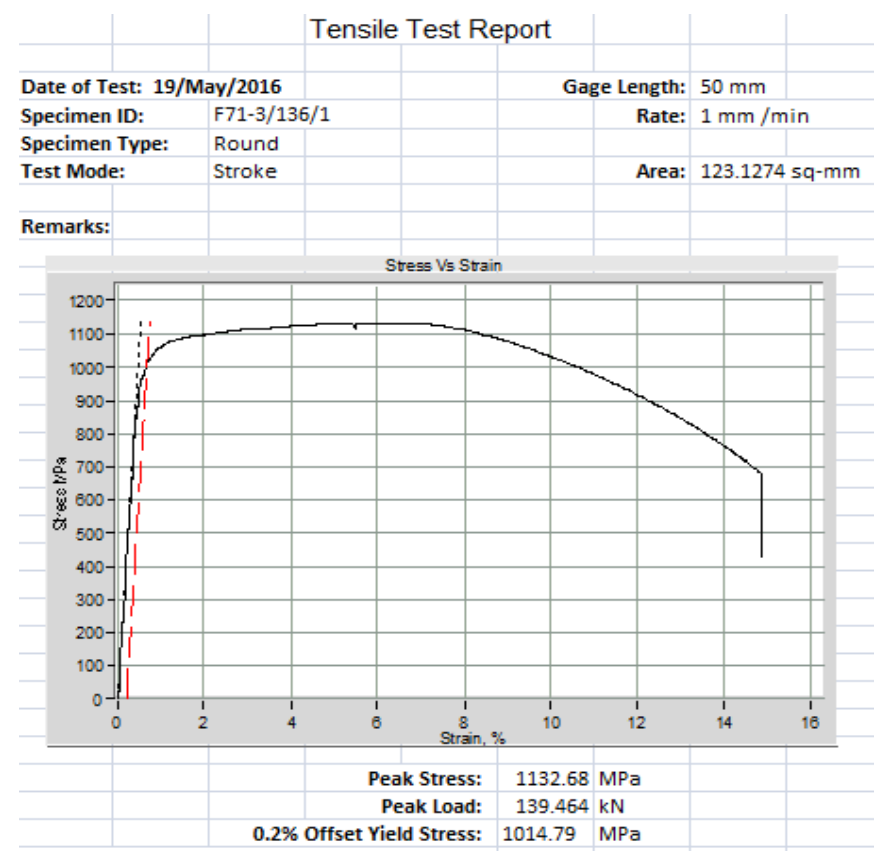

Figure 3: Stress vs Strain plot for Specimen 1

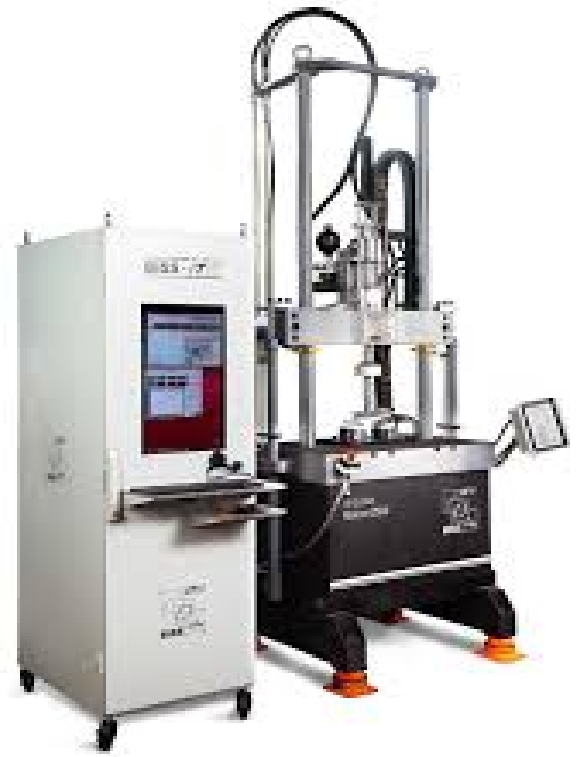

Figure 4: BiSS Universal Testing Machine 
Table 5: Experimental values $\epsilon_{a}, \epsilon_{b}$ and $\epsilon_{c}$ obtained from the strain gauge rosettes at locations 1,2 and 3

\begin{tabular}{|c|c|c|c|c|c|c|c|c|c|}
\hline \multirow{2}{*}{$\begin{array}{l}\text { Pressure } \\
\text { in ksc }\end{array}$} & \multicolumn{3}{|c|}{ location 1} & \multicolumn{3}{|c|}{ location 2} & \multicolumn{3}{|c|}{ location 3} \\
\hline & $1 ' 00$ & $1 ' 45$ & 1'90 & $2^{\prime} 00$ & $2 ' 45$ & $2 ' 90$ & $3 \mathrm{O} 00$ & $3 ' 45$ & $3 ' 90$ \\
\hline 0 & 2 & 2 & 2 & 0 & -1 & 0 & 1 & 0 & 1 \\
\hline 10 & 357 & 675 & 1064 & 28 & 149 & 254 & 556 & 351 & 127 \\
\hline 0 & 7 & 16 & 25 & 1 & 4 & 5 & 5 & 2 & -2 \\
\hline 10 & 357 & 673 & 1065 & 28 & 150 & 253 & 555 & 350 & 126 \\
\hline 0 & 5 & 11 & 19 & 0 & 2 & 4 & 4 & 1 & -2 \\
\hline 35 & 1155 & 2116 & 3330 & 94 & 533 & 914 & 2181 & 1347 & 561 \\
\hline 0 & 1 & 1 & 1 & 1 & 1 & 1 & 1 & 1 & 1 \\
\hline 10 & 357 & 667 & 953 & 29 & 150 & 251 & 553 & 355 & 130 \\
\hline 20 & 692 & 1273 & 1898 & 55 & 301 & 510 & 1185 & 757 & 304 \\
\hline 30 & 1010 & 1830 & 2757 & 81 & 455 & 775 & 1818 & 1152 & 478 \\
\hline 48 & 1516 & 2760 & 4278 & 129 & 735 & 1263 & 3032 & 1866 & 781 \\
\hline 51 & 1591 & 2909 & 4547 & 137 & 782 & 1346 & 3255 & 1993 & 834 \\
\hline 56 & 1722 & 3162 & 4993 & 150 & 862 & 1487 & 3651 & 2225 & 930 \\
\hline 56 & 1713 & 3172 & 5052 & 151 & 862 & 1488 & 3711 & 2254 & 939 \\
\hline 51 & 1574 & 2929 & 4660 & 138 & 784 & 1348 & 3364 & 2044 & 848 \\
\hline 48 & 1485 & 2782 & 4441 & 129 & 736 & 1265 & 3175 & 1927 & 796 \\
\hline 40 & 1251 & 2391 & 3856 & 108 & 612 & 1048 & 2688 & 1620 & 660 \\
\hline 30 & 947 & 1876 & 3070 & 82 & 457 & 778 & 2068 & 1233 & 488 \\
\hline 20 & 631 & 1323 & 2222 & 56 & 303 & 511 & 1444 & 841 & 316 \\
\hline 10 & 301 & 733 & 1298 & 29 & 152 & 252 & 825 & 449 & 145 \\
\hline 0 & -50 & 80 & 258 & 0 & 2 & -3 & 280 & 103 & 20 \\
\hline
\end{tabular}

Table 6: Experimental values $\epsilon a, \epsilon b$ and $\epsilon c$ at locations 4, 5, 6 and7

\begin{tabular}{|c|c|c|c|c|c|c|c|c|c|c|c|c|}
\hline \multirow{2}{*}{$\begin{array}{l}\text { Pressure } \\
\text { inksc }\end{array}$} & \multicolumn{3}{|c|}{ locerion 4} & \multicolumn{3}{|c|}{ location 5} & \multicolumn{3}{|c|}{ location 6} & \multicolumn{3}{|c|}{ location 7} \\
\hline & 400 & $4 / 45$ & 490 & 5,00 & 545 & 590 & 600 & 6.45 & 690 & 600 & 645 & 590 \\
\hline 0 & 3 & 2 & 1 & 1 & 1 & 1 & 2 & 2 & 0 & 6 & 4 & 2 \\
\hline 10 & 634 & 379 & 110 & 431 & 182 & -21 & 846 & 507 & 203 & 326 & 262 & 180 \\
\hline 0 & 12 & 8 & 1 & 1 & -4 & -7 & 18 & 10 & 4 & -6 & 1 & -1 \\
\hline 10 & 634 & 379 & 108 & 432 & 181 & -21 & 846 & 507 & 203 & 324 & 261 & 179 \\
\hline 0 & 9 & 6 & 2 & 2 & -3 & 6 & 14 & 8 & 4 & -5 & -1 & -2 \\
\hline 35 & 2283 & 1360 & 446 & 1862 & 991 & 232 & 2669 & 1558 & 630 & 1432 & 1032 & 683 \\
\hline 0 & 1 & 1 & 1 & 1 & 1 & 1 & 1 & 1 & 1 & 1 & 1 & 1 \\
\hline 10 & 634 & 379 & 108 & 438 & 291 & -16 & 843 & 503 & 202 & 338 & 266 & 184 \\
\hline 20 & 1285 & 766 & 243 & 999 & 502 & 73 & 1598 & 942 & 382 & 782 & 577 & 381 \\
\hline 30 & 1927 & 1148 & 375 & 1566 & 829 & 179 & 2299 & 1348 & 548 & 1234 & $8 \mathrm{~d} 4$ & 569 \\
\hline 48 & 3131 & 1867 & 626 & 2627 & 1445 & 394 & 3503 & 1995 & 834 & 1979 & 1388 & 961 \\
\hline 51 & 3343 & 1996 & 665 & 2815 & 1533 & 433 & 3681 & 2078 & 882 & 2088 & 1462 & 2038 \\
\hline 56 & 3739 & 2240 & 737 & 3163 & 1753 & 501 & 3976 & 2224 & 967 & 2281 & 1593 & 1164 \\
\hline 56 & 3790 & 2272 & 750 & 3199 & 1766 & 503 & 3979 & 2209 & 969 & 2262 & 1577 & 1184 \\
\hline 51 & 3443 & 2059 & 675 & 2887 & 1581 & 439 & 3676 & 2040 & 890 & 2038 & 1430 & 1079 \\
\hline $4 \mathrm{~S}$ & 3255 & 1948 & 634 & 2712 & 1478 & 401 & 3487 & 1930 & 843 & 1895 & 1335 & 1023 \\
\hline 40 & 2765 & 1654 & 527 & 2259 & 2221 & 306 & 2991 & 1641 & 722 & 1523 & 1090 & 880 \\
\hline 30 & 2144 & 1283 & 399 & 1688 & 876 & 189 & 2351 & 1266 & 563 & 1060 & 782 & 698 \\
\hline 20 & 1517 & 908 & 261 & 1119 & 549 & 81 & 1684 & 877 & 398 & 604 & 475 & 510 \\
\hline 10 & 884 & 530 & 129 & 561 & 239 & 8 & 976 & 464 & 223 & 161 & 172 & 328 \\
\hline 0 & 248 & 154 & 27 & 110 & 48 & 12 & 195 & -3 & 27 & -162 & .78 & 140 \\
\hline
\end{tabular}

Table7: Principal stresses and equivalent stress at locations 1, 2 and 3 


\begin{tabular}{|c|c|c|c|c|c|c|c|c|c|}
\hline \multirow{2}{*}{$\begin{array}{c}\text { Pressure } \\
\text { in ksc }\end{array}$} & \multicolumn{3}{|c|}{ Iocation 1 } & \multicolumn{3}{c|}{ location 2 } & \multicolumn{3}{c|}{ Iocation 3} \\
\cline { 2 - 11 } & $\sigma 1$ & $\sigma 2$ & $\sigma \mathrm{V}$ & $\sigma 1$ & $\sigma 2$ & $\sigma \mathrm{V}$ & $\sigma 1$ & $\sigma 2$ & $\sigma \mathrm{V}$ \\
\hline 0 & 225.79 & 240.39 & 110 & 219.56 & 219.56 & 110 & 168.42 & 194.15 & 110 \\
\hline 10 & 27.92 & 16.15 & 24.28 & 6.34 & 2.51 & 5.53 & 14.32 & 7.09 & 12.4 \\
\hline 0 & 0.66 & 0.35 & 0.57 & 0.14 & 0.06 & 0.11 & 0.1 & -0.01 & 0.11 \\
\hline 10 & 27.95 & 16.15 & 24.3 & 6.32 & 2.5 & 5.51 & 14.28 & 7.05 & 12.37 \\
\hline 0 & 0.5 & 0.26 & 0.43 & 0.1 & 0.03 & 0.09 & 0.08 & -0.02 & 0.09 \\
\hline 35 & 76.06 & 46.31 & 66.4 & 22.57 & 8.85 & 19.7 & 53.25 & 28.18 & 46.14 \\
\hline 0 & 0.03 & 0.03 & 0.03 & 0.03 & 0.03 & 0.03 & 0.03 & 0.03 & 0.03 \\
\hline 10 & 25.32 & 15.4 & 22.1 & 6.29 & 2.51 & 5.48 & 14.27 & 7.13 & 12.36 \\
\hline 20 & 48.36 & 29.38 & 42.2 & 12.7 & 5.01 & 11.08 & 30.3 & 15.76 & 26.25 \\
\hline 30 & 66.3 & 40.94 & 57.95 & 19.21 & 7.54 & 16.76 & 45.35 & 24.05 & 39.3 \\
\hline 48 & 89.23 & 55.94 & 78.1 & 30.87 & 12.15 & 26.94 & 69.71 & 37.63 & 60.43 \\
\hline 51 & 92.2 & 57.79 & 80.7 & 32.8 & 12.92 & 28.62 & 73.47 & 39.79 & 63.7 \\
\hline 56 & 96.55 & 60.66 & 84.53 & 36.04 & 14.21 & 31.44 & 79.59 & 43.43 & 69.02 \\
\hline 56 & 97.04 & 60.6 & 84.9 & 36.07 & 14.24 & 31.47 & 80.43 & 43.85 & 69.75 \\
\hline 51 & 93.28 & 57.74 & 81.54 & 32.86 & 12.96 & 28.67 & 75.16 & 40.57 & 65.16 \\
\hline 48 & 90.9 & 55.79 & 79.4 & 30.92 & 12.16 & 26.98 & 72.06 & 38.63 & 62.46 \\
\hline 40 & 83.57 & 50.04 & 72.84 & 25.8 & 10.13 & 22.51 & 63.27 & 33.27 & 54.82 \\
\hline 30 & 71.21 & 41.06 & 61.91 & 19.29 & 7.58 & 16.83 & 50.56 & 25.84 & 43.79 \\
\hline 20 & 54.55 & 29.87 & 47.31 & 12.74 & 5.04 & 11.11 & 36.23 & 17.8 & 31.38 \\
\hline 10 & 32.91 & 16.4 & 28.5 & 6.31 & 2.52 & 5.5 & 20.86 & 9.41 & 18.09 \\
\hline 0 & 5.9 & 0.63 & 5.61 & 0.02 & -0.11 & 0.12 & 7.05 & 2.37 & 6.21 \\
\hline
\end{tabular}

Table 8: Principal stresses and equivalent stress at locations 4, 5, 6 and 7

\begin{tabular}{|c|c|c|c|c|c|c|c|c|c|c|c|c|}
\hline \multirow{2}{*}{$\begin{array}{l}\text { Presuse } \\
\text { in kse }\end{array}$} & \multicolumn{3}{|c|}{ location 4} & \multicolumn{3}{|c|}{ location 5} & \multicolumn{3}{|c|}{ location 6} & \multicolumn{3}{|c|}{ location 7} \\
\hline & 01 & 02 & $g \mathrm{r}$ & al & 02 & $\sigma \mathrm{v}$ & 01 & 02 & or & 01 & 02 & ov \\
\hline 0 & 600.73 & 542.55 & 110 & 139.63 & 179.75 & 110 & 150.64 & 219.29 & 110 & 485.64 & 424.87 & 110 \\
\hline 10 & 16.05 & 7.24 & 1392 & 10.27 & 26 & 9.25 & 21.74 & 10.98 & 18.83 & 9.19 & 6.7 & 8.23 \\
\hline 0 & 0.3 & 0.11 & 0.26 & -0.02 & -0.16 & 0.15 & 0.46 & 023 & 0.4 & -0.02 & -0.2 & 0.19 \\
\hline 10 & 16,03 & 7.19 & 1391 & 10.29 & 2.6 & 9.27 & 21.74 & 10.98 & 18.83 & 9.13 & 6.66 & 8.18 \\
\hline 0 & 0.23 & 0.11 & 0.2 & 001 & -0.14 & 0.14 & 037 & 0.2 & 0.32 & -0.06 & -0.16 & 0.14 \\
\hline 35 & 54.52 & 26.26 & 47.23 & 44.68 & 18.67 & 38.87 & 62.8 & 32.48 & 54.4 & 38.38 & 2624 & 33.98 \\
\hline 0 & 0.03 & 0.03 & 0.03 & 0.03 & 0.03 & 0.03 & 0.03 & 0.03 & 0.03 & 0.03 & 0.03 & 0.03 \\
\hline 10 & 16.03 & 7.19 & 13.91 & 10.46 & 2.77 & 939 & 21.66 & 10.93 & 18.76 & 9.5 & 6.89 & 8.5 \\
\hline 20 & 32.15 & 15.02 & 27.86 & 24.41 & 8.95 & 2139 & 40.05 & 20.36 & 34.69 & 21.48 & 1478 & 19,04 \\
\hline 30 & 46.95 & 22.4 & 40.67 & 37.98 & 15.43 & 33.08 & 55.5 & 28.56 & 48.07 & 33.22 & 2231 & 29.33 \\
\hline 48 & 70.49 & 3497 & 61.05 & 60.65 & 27.18 & 52.62 & 77.21 & 40.79 & 669 & 51.68 & 35.71 & 45.83 \\
\hline 51 & 73.96 & 36.84 & 64.05 & 64.21 & 29.13 & 55.69 & 79.91 & 42.45 & 6925 & 54.31 & 37.93 & 48.25 \\
\hline 56 & 79.92 & 4014 & 69.21 & 70,36 & 32.52 & 60.99 & 84.09 & 4517 & 72.89 & 58.73 & 4154 & 523 \\
\hline 56 & 80.64 & 40.62 & 69.84 & 70.92 & 32.75 & 61.48 & 84.16 & 45.18 & 72.95 & 58.54 & 41.8 & 52.22 \\
\hline 51 & 75.48 & 3754 & 65.37 & 65.48 & 29.67 & 56.79 & 79.93 & 42.49 & 6927 & 53.65 & 38.42 & 47.89 \\
\hline 48 & 72.47 & 35.77 & 62.76 & 62.23 & 2783 & 53.99 & 77.11 & 40.75 & 66.82 & 50.49 & 36.41 & 45.13 \\
\hline 40 & 63.86 & 30.88 & 55.31 & 53.21 & 2294 & 46.23 & 68.95 & 35.88 & 59.73 & 4189 & 3101 & 3765 \\
\hline 30 & 51.47 & 24.2 & 446 & 40.71 & 16.48 & 35.47 & 56.8 & 28.93 & 49.19 & 30.51 & 23.76 & 2776 \\
\hline 20 & 37.44 & 17.03 & 32.47 & 27.26 & 997 & 23.89 & 42.3 & 21 & 36.63 & 18.98 & 15.81 & 17.61 \\
\hline 10 & 22.11 & 9.47 & 19.21 & 13.5 & 3.83 & 12.05 & 25.3 & 11.99 & 2192 & 927 & 5.77 & 8.1 \\
\hline 0 & 6.21 & 2.43 & 5.42 & 2.78 & 106 & 2.43 & 5.88 & 1.09 & 542 & 2.45 & -3.14 & 4.85 \\
\hline
\end{tabular}

\section{AUTHOR PROFILE}

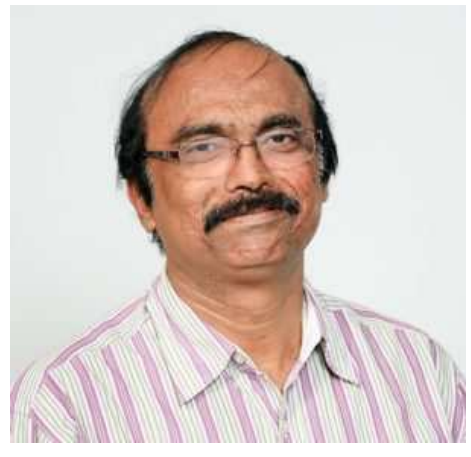

Dr G Laxmaiah is working currently as a Professor in the department of Mechanical Engineering, Chaitanya Bharathi institute of technology (CBIT), Hyderabad, graduated from Nagarjuna University in 1993 and obtained his postgraduation with Machine Design from Andhra University in 1996. He obtained his $\mathrm{PhD}$ from Osmania University in 2013. He has 23 years of teaching experience. He has published 15 papers in various national and international journals and conferences. His area of research is Design and Vibrations. Presently he is guiding 4 Ph.D scholars. He is the member SAE and life member of ISTE,New Delhi. 

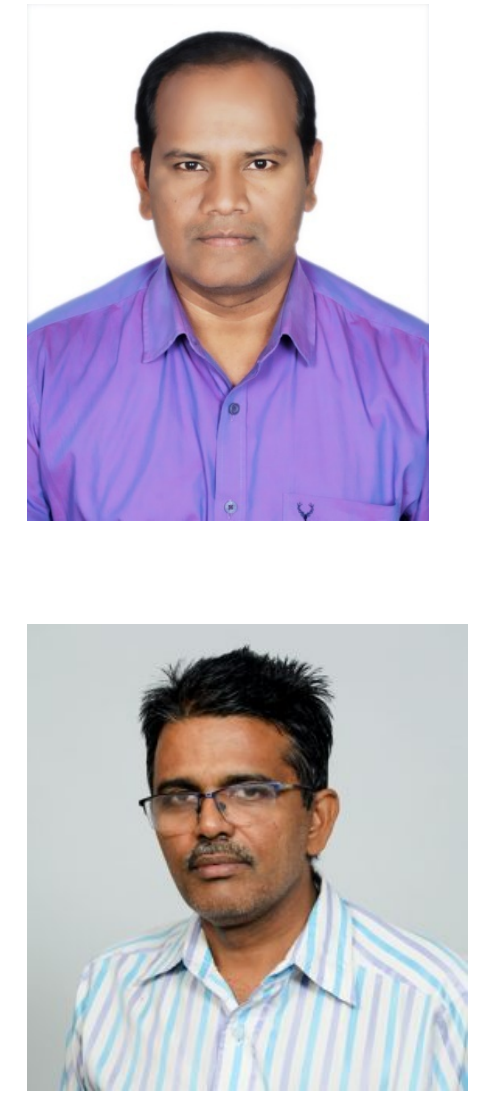

DrSSolomonRajworkingasAssociateProfessorProfessor in the department of Mechanical Engineering, Chaitanya Bharathi institute of technology (CBIT), Hyderabad,obtainedhisBTechin

MechanicalEngineeringfromKakatiyaUnivarsity,Warangal(2000). Later,hodidhisM Tech in Solid Mechanics and Design from IlTKanpur(2004).HehascompletedhisPh.DfromOsmaniaUniversity(2017)inthe areaofCompositeMaterials. Hehasputin16yearsofTeachingexperionce.HisAreasof Interests are Solid Mechanics,Machine Design, Composite Materials, Mechanical Vibrations and Finite Element Analysis. He has published Research Papers in Internationalleveljournalsandconferences

Dr.P.V.R.Ravindra Reddy, presently working as Professor of Mechanical Engineering,CBIT was graduated from REC (Presently NIT), Rourkela in 1993 in Mechanical Engineering, obtained M.Tech (Manufacturing Engg.) from NIFFT, Ranchi in 1996, and was awarded with Ph.D from Osmania University in 2010. He worked as Engineer (Development) in Hindustan Gas and Industries Ltd, An Aditya Birla concern for 2 years and Joined CBIT in 1998 became Associate Professor in the year 2006 and Professor in 2013. He has published 5 papers in international journals, 25 papers in National Journals, 6 papers in international conferences and 18 papers in national conferences. He has successfully completed a research project of worth 9.95 lakhs from defense labs and presently carrying out another project of 9.9 lakhs. He is the coordinator for ISO 9001:2015 implementation in CBIT. Presently he is guiding 4 Ph.D scholars. $\mathrm{He}$ is the member of Institute of Engineers India and Society of Manufacturing Engieers.His area of research is metal forming and welding. 